\title{
PARQUES EÓLICOS OFFSHORE NO BRASIL E OS POTENGIAIS IMPACTOS SOCIAIS: APLICAÇÃO DE MATRIZES SWOT
}

\author{
Offshore wind farms in Brazil and the potential social impacts: \\ application of SWOT Analysis
}

\author{
Thomaz Willian de Figueiredo Xavier ${ }^{1}$, Adryane Gorayeb Nogueira Caetano ${ }^{2}$, Christian Brannstrom ${ }^{3}$ \\ ${ }^{1}$ Programa de Pós-graduação em Geografia, Universidade Federal do Ceará, \\ Bolsista PREX, Capes. E-mail: txavier@alu.ufc.br \\ ${ }^{2}$ Departamento de Geografia, Universidade Federal do Ceará,Bolsista de Produtividade em \\ Pesquisa 2, CNPq, E-mail: gorayeb@ufc.br \\ ${ }^{3}$ Departamento de Geografia, Texas A\&M University, E-mail: cbrannst@geos.tamu.edu
}

\begin{abstract}
RESUMO
Com o constante aumento dos investimentos no setor elétrico, surgiram iniciativas internacionais para introdução de turbinas eólicas em ambientes marinhos (offshore). No Brasil, tem-se articulado três iniciativas distintas para a construção de parques eólicos marinhos. Estima-se que surjam diferentes impactos sociais envolvendo as populações costeiras que fazem uso dos recursos oceânicos e marítimos próximos. O objetivo da pesquisa foi analisar, de forma participativa, a introdução de um projeto de parque eólico offshore em águas litorâneas da costa oeste cearense. Utilizou-se a elaboração de Matrizes SWOT com os pescadores das comunidades próximas ao projeto como ferramenta para a realização do diagnóstico participativo local. Foram indicadas 36 forças, 27 fraquezas, 20 oportunidades e 13 ameaças. Foi possível entender que garantir a inserção social promove consideráveis ganhos. O efetivo engajamento público deve seguir métodos que permitam transparecer as informações relevantes aos moradores, promovendo discussões fluidas e didáticas e tomadas de decisão de forma participativa, garantindo o diálogo entre empreendedores, Estado e comunidades atingidas.
\end{abstract}

Palavras-chave: avaliação de impacto social, Matrizes SWOT, participação pública, parque eólico offshore. 


\section{ABSTRACT}

With the steady increase in investments in the electricity sector, international initiatives have emerged for the introduction of wind turbines in offshore environments. In Brazil, three distinct initiatives have been articulated for the construction of marine wind farms. It is estimated that different social impacts will arise involving coastal populations making use of nearby ocean and maritime resources. The objective of the research was to analyze, in a participatory manner, the introduction of an offshore wind farm project in coastal waters of the west coast of Ceara, Brazil. It was used the elaboration of SWOT Analysis with the fishermen of the communities near the project, as a tool for the local participative diagnosis. 36 Strengths, 27 Weaknesses, 20 Opportunities and 13 Threats were indicated. It was possible to understand that ensuring social inclusion promotes considerable gains. Effective public engagement should follow methods that allow the relevant information to be transparent to residents, promoting fluid and didactic discussions and decision-making in a participatory manner, ensuring dialogue between entrepreneurs, the state and affected communities.

Keywords: offshore wind farm, SWOT Analysis, social impact assessment, public participation.

\section{INTRODUÇÃO}

Formas de produção energética de baixo carbono tornaram-se imprescindíveis, principalmente por contribuírem na redução da emissão de gases do efeito estufa. A partir do Protocolo de Quioto em 1997, mudanças significativas começaram a ser feitas no âmbito da produção energética mundial. Sistemas que produzem energia por fontes renováveis (marés, vento, sol, geotermia etc.) vêm, desde então, adquirindo espaço e avançando tecnologicamente. Nesse contexto, a energia eólica ganhou espaço devido ao seu baixo custo e rápida instalação, à competitividade econômica da energia produzida e à alta capacidade de produção energética (Viterbo, 2008; Melo, 2013). Com o aumento dos investimentos no setor, as áreas para instalação de novos parques eólicos (onshore) tornaram-se escassas, sobretudo em países com pouca extensão territorial, surgindo, assim, iniciativas para introdução de turbinas eólicas em ambientes marinhos (offshore). Além disso, atitudes governamentais, como a proibição da construção de novas usinas nucleares na Alemanha, impulsionaram o desenvolvimento de parques eólicos marinhos - PEM (Viterbo, 2008).

Parques eólicos offshore são cobiçados pelos investidores devido a densidades de energia consideravelmente maiores que 1,5 watts por metro quadrado comumente obtidas em parques eólicos onshore (Possner \& Caldeira, 2017). Uma recente revisão indicou que a qualidade do vento para parques eólicos offshore é alta em razão da baixa intensidade de turbulência e atrito existentes no mar (Zheng et al., 2016). Além disso, os autores indicaram que a aceitação pública pode ser maior para os parques eólicos offshore em comparação com os equivalentes terrestres, levando à consideração de que "os recursos de energia eólica offshore têm um espaço de desenvolvimento efetivamente ilimitado" (p. 1242, tradução nossa).

O primeiro PEM no mundo, o Vindeby, esteve localizado no Mar do Norte nas proximidades de Great Belt, na Dinamarca, cuja operação ocorreu entre 1991 e 2017. À medida que a tecnologia apresentou viabilidade econômica, outros países introduziram seus pri- 
meiros PEM, como, por exemplo: o Thorntonbank, na Bélgica em 2009; o Thanet, no Reino Unido, e o Chenjiagang (Jiangsu) Xiangshui, na China em 2010; o Bard Offshore 1, na Alemanha em 2013; o Gemini, na Irlanda em 2017; e o BlockIsland, nos EUA em 2018. Atualmente, o maior parque eólico marinho do mundo, em termos de capacidade instalada (CI), é o Walney Extension, localizado na costa de Cumbria, no Reino Unido, cuja instalação foi finalizada em setembro de 2018. São 87 turbinas, totalizando $659 \mathrm{MW}$ de CI, o que possibilita o abastecimento de aproximadamente 600 mil residências. Hoje, são mais de 100 PEM ativos no mundo, totalizando cerca de 19 GW (19 mil MW) de capacidade instalada (Gwec, 2018). Trata-se de uma fonte de energia consolidada, apresentando poder econômico considerável no mercado energético.

O Brasil, no contexto mundial, configura-se como um dos principais produtores de energia eólica (onshore). São mais de 7.000 torres em 583 parques eólicos em 12 estados brasileiros, totalizando 14,71 GW de CI (Abeeólica, 2019). Recentemente, por meio do PLS $n^{\circ} 484 / 2017^{1}$ (Brasil, 2017), a concepção do marco regulatório eólico-marinho foi proposta em conjunto com os projetos de usinas fotovoltaicas offshore. Nesse contexto, tem-se apresentado três iniciativas distintas para a construção de PEM no Brasil. Uma é conduzida pela Petrobras, cujo objetivo visa instalar apenas um aerogerador como protótipo para prospecção econômica, o qual será instalado ao lado da plataforma offshore de petróleo PUB-3 em Guamaré/RN. Outra, o Parque Eólico Offshore Caucaia Parazinho - Iparana, além de objetivar a produção de energia, visa introduzir o PEM em área de forte erosão na zona costeira do município de Caucaia/CE (Região Metropolitana de Fortaleza, no litoral oeste), servindo como "barreira" artificial para contenção dos processos erosivos ali existentes. Já a terceira, o Complexo de Geração Eólico-Marinha Asa Branca I (CGEMAB I), o qual é produto de análise neste texto, tem sua área localizada em águas costeiras dos municípios de Itarema e Amontada, no litoral oeste cearense, sendo a região onde se planeja introduzi-lo fortemente utilizada por práticas pesqueiras ${ }^{2}$.

As duas iniciativas relacionadas à região costeira do Ceará, diferentes do projetado pela Petrobras, serão instaladas, caso tenham todas as autorizações legais concedidas, em áreas bem próximas à zona costeira. As projeções são para que sejam concebidos entre 2 e $10 \mathrm{~km}$ da linha da costa de seus respectivos municípios. A partir dessa premissa, estima-se que surjam diferentes impactos sociais envolvendo as populações costeiras que fazem uso direto e indireto dos recursos oceânicos e marítimos próximos. Assim, impacto social pode ser compreendido como todas as consequências sociais e culturais para as populações humanas, sucedidas de quaisquer ações públicas ou privadas que alterem as maneiras pelas quais as pessoas vivem, trabalham, se relacionam e se organizam para atender às suas necessidades (ICGPSIA, 1994) ${ }^{3}$. Nesse aspecto, o que tem sido articulado no âmbito social, como geralmente ocorre em outros setores, resume-se aos quantitativos que seriam produzidos na geração de empregos a partir da introdução dos projetos. De forma geral, percebe-se que é dada maior atenção aos impactos sociais positivos sem que considerem as aná-

\footnotetext{
${ }^{1}$ De autoria do Senador Fernando Collor, o projeto já passou pelas seguintes comissões do Senado: Comissões de Constituição, Justiça e Cidadania; de Assuntos Econômicos; e de Serviços de Infraestrutura. Em dezembro de 2018 seguiu para a Câmara dos Deputados para encaminhamentos nos trâmites legais.

2 Para mais informações sobre os projetos: https://bit.ly/2SBh7f5 e https://bit.ly/2E4hN4u.

${ }^{3} \mathrm{O}$ conceito apresentado trata-se da primeira definição publicada em termos internacionais no âmbito da AIS e compete fielmente às discussões aqui propostas, porém, indica-se que sejam realizadas leituras adicionais no Social Impact Assessment: guidance for assessing and managing the social impactos of projects (Vanclay et al., 2015) publicado pela International Association for Impact Assessment (IAIA).
} 
lises dos efeitos negativos cumulativos ou não, a médio e longo prazo sobre as populações. Assim, quais seriam os principais impactos decorrentes da inserção dos PEM sobre as comunidades litorâneas em águas costeiras brasileiras e quais seriam os meios para avaliá-los com eficácia? É preciso que sejam considerados tanto o papel social dos territórios marinhos no Brasil (Telles, 2018) como a necessidade de participação pública efetiva na gênese do setor eólico-marinho brasileiro. A participação pública, através das audiências públicas, tem sido, majoritariamente, utilizada como simples apresentações de resultados nos estágios finais dos processos de licenciamento e, embora existam debates, poucas mudanças acabam sendo feitas (Negev et al., 2013; Faria \& Silva, 2017). Tal realidade remete à necessidade de novos modelos de inserção pública.

Nesse sentido, a pesquisa propõe analisar a introdução de um parque eólico marinho em águas costeiras do Ceará, o CGEMAB I, destacando os potenciais impactos nas comunidades litorâneas através da aplicação de métodos participativos. Trata-se de discussões e resultados iniciais de pesquisa em nível de tese ${ }^{4}$. A metodologia da pesquisa é fundamentada na Avaliação de Impactos Sociais (AIS). Articulou-se a elaboração de Matrizes SWOT (Strengths, Weaknesses, Opportunities, and Threats) como ferramenta para a realização do diagnóstico participativo local, configurando-se como meio para imprimir os impactos positivos e negativos que seriam gerados a partir da inserção do PEM analisado.

\section{FUNDAMENTOS NA AVALIAÇÃO DE IMPACTOS SOCIAIS (AIS) E O USO DA MATRIZ SWOT}

Diretrizes de AIS têm sido empregadas como guias para processos de gestão social em diferentes jurisdições, apresentando bons resultados. É possível ver exemplos em países como Austrália, África do Sul e Filipinas (Esteves; Franks \& Vanclay, 2012). Além disso, agências de fomento internacionais, como é o caso do Banco Interamericano de Desenvolvimento (BID), têm inserido, em suas metodologias para análise de subsídio, mecanismos pautados na AIS (Kvam, 2018). O processo é, basicamente, fundamentado nas seguintes características: participação pública com espaços para que as comunidades discutam sobre o futuro desejado, a aceitabilidade dos prováveis impactos e benefícios e, ainda, a possibilidade de contribuírem no processo de concepção do projeto; obtenção de eficiente compreensão de quais comunidades seriam susceptíveis à ação proposta; identificação das necessidades e dos desejos das comunidades; apresentação de escopo das principais questões sociais; coleta de dados para apoio à decisão; previsão das possíveis mudanças que resultariam da iniciativa proposta; fornecimento de sentido às mudanças previstas, determinando como os diferentes grupos reagiriam; avaliação de alternativas; identificação de formas para mitigar potenciais impactos e maximizar as oportunidades; desenvolvimento de planos de monitoramento; facilitação na conciliação entre as comunidades e o desenvolvedor por meio de princípios sociais; auxílio ao proponente na preparação dos planos para gestão dos impactos e, por fim, garantia na segurança no comprimento dos acordos firmados (Vanclay \& Esteves, 2011).

Basicamente, as atividades a serem executadas são divididas em quatro fases principais: 1) entender os problemas; 2) prever, analisar e avaliar as prováveis trajetórias dos

\footnotetext{
${ }^{4}$ Em processo de elaboração no Programa de Pós-Graduação em Geografia na Universidade Federal do Ceará sob o título Prognóstico socioambiental participativo: parques eólicos offshore em águas costeiras do Brasil.
} 
impactos; 3) desenvolver e implementar estratégias; e 4) projetar e efetivar programas de monitoramento (Vanclay et al., 2015). Segundo os autores, os perfis comunitários podem ser preparados através de profundos debates sobre os ativos, as forças e as fraquezas nas comunidades. Afirmam ainda que o uso de abordagens e métodos participativos providenciam, entre outras, oportunidade para validação de dados, possibilidade de subsídios para resolver os conflitos sobre uso dos recursos, auxílio na melhoria do design do projeto etc. Embora a Matriz SWOT tenha sido concebida para gestão de grandes corporações há mais de 50 anos, tem sido aplicada como mecanismo de diagnóstico, principalmente ligado à construção de estratégias para gestão de pequenos grupos (Helms \& Nixon, 2010). Sua aplicação tem providenciado gestões eficazes em diferentes domínios, como, por exemplo: bacias hidrográficas; rios e florestas; florestas de mangue; comunidades de pescadores de ostras; estruturação de serviços ecossistêmicos etc. Yavuz e Baycan (2013) consideram que essa ferramenta pode ser empregada no auxílio à tomada de decisão participativa. De La Cruz-González et al. (2018) utilizaram essa matriz em conjunto com o diagnóstico participativo rural (DRP) para analisar, em suporte a partir de gestões comunitárias lideradas por pescadores locais, a evolução da administração da pesca de ostras ao longo da costa de Nayarit, no México. Assim, o uso das Matrizes SWOT está diretamente ligada às três fases iniciais da AIS e, nesta pesquisa, foi usada, com os pescadores, como modelo para incitar discussão sobre os possíveis impactos sociais e ambientais da implantação de parques eólicos offshore.

\section{PROCEDIMENTOS METODOLÓGICOS}

A área projetada para o CGEMAB I está localizada a cerca de $200 \mathrm{~km}$ de Fortaleza nas

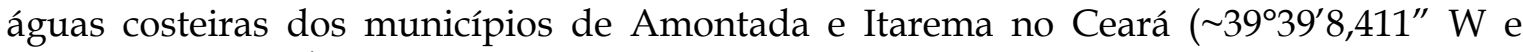
$\sim 2^{\circ} 57^{\prime} 16,927^{\prime \prime}$ S). É previsto que o complexo seja dividido em dez parques eólicos, cada um com 5 aerogeradores, totalizando 400 MW de CI (Figura 1a). As atividades foram realizadas no segundo semestre de 2018, nas seguintes comunidades de pescadores artesanais: Porto dos Barcos e Torrões, em Itarema, e Moitas e Caetanos, em Amontada. A escolha dessas comunidades deu-se em razão da proximidade com a área projetada para Colônias de Pescadores (Colônias Z-18 e Z-19) que reúnem como associados grande parte da construção do CGEMAB I e por possuírem pescadores do litoral oeste do estado.

A linha de transmissão (LT) está planejada para ir até o Complexo Industrial e Portuário do Pecém S/A em São Gonçalo do Amarante, CE, e então ser interligado ao sistema nacional de distribuição (Figura $1 b$ ). Vale ressaltar que as atividades para elaboração das Matrizes SWOT foram realizadas com pescadores artesanais filiados às Colônias Z-18 e Z-19 dos municípios de Amontada e Itarema, respectivamente, totalizando 47 participantes ${ }^{5}$. Devido ao caráter exploratório da pesquisa, a escolha dos participantes deu-se por amostragem aleatória (voluntários). Considera-se a amostragem representativa, em razão de terem sido articulados os conhecimentos tradicionais dos pescadores. Em Caetanos, os trabalhos foram divididos em dois momentos, um em Caetanos de Baixo e outro em Caetanos de Cima. Essa divisão foi realizada para evitar a potencialização dos conflitos internos já existentes. No total, foram realizadas cinco atividades em grupo, no período de julho a setembro de 2018 .

\footnotetext{
${ }^{5}$ A pesquisa passou por apreciação pelo Comitê de Ética em Pesquisa da UFC, obtendo deferimento: Parecer n 3.172 .989
} 
Figura 1 - Área planejada para o CGEMAB I, comunidades onde os trabalhos foram realizados e área impactada pelo "efeito esteira" (a); e extensão da linha de transmissão (LT) planejada (b)

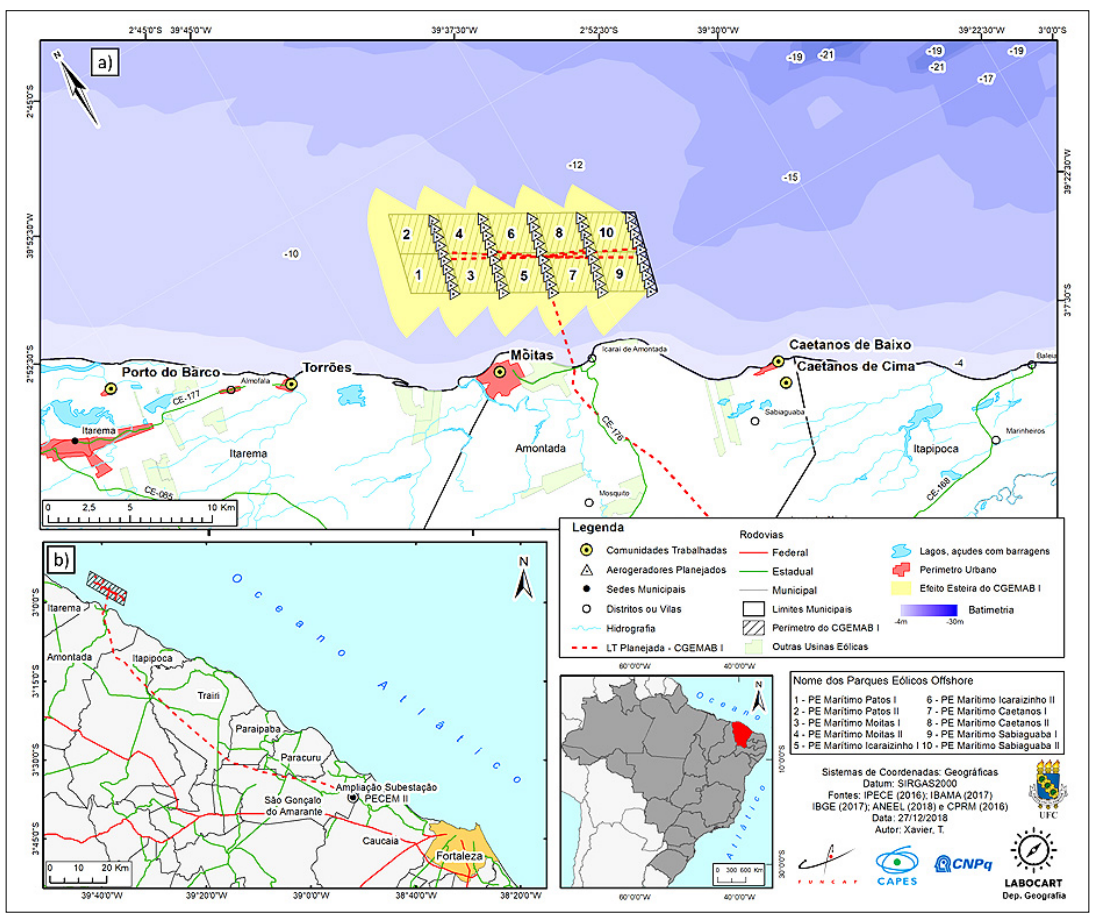

Fonte: Acervo Labocart (2018).

As atividades em grupo seguiram a seguinte ordem: I) período de contextualização e apresentação dos objetivos da pesquisa; II) discussões sobre a realidade local; III) elaboração das Matrizes SWOT (Almasi; Milow \& Zakaria, 2018; De La Cruz-González et al., 2018; Helms \& Nixon, 2010); e IV) construção da Cartografia Social da Pesca (Acselrad, 2008; Brown \& Kyttä, 2014; Chaves, 2013; Corbett et al., 2006; Costa et al., 2016; Mendes; Gorayeb \& Brannstrom, 2016). Neste trabalho são apresentados apenas os resultados e as discussões relacionadas à elaboração das Matrizes SWOT.

Foram apresentados alguns questionamentos norteadores no início das discussões, com o intuito de instigar os participantes a refletirem sobre seu cotidiano: quais são as problemáticas relativas à pesca na região? Quais são as espécies de pescado encontradas na região? Quais são as artes de pesca (materiais) mais utilizadas e como as diferentes espécies de pescado são capturadas? Quais são os tipos de embarcações utilizadas, a quantidade de pescadores por embarcação e o volume de pescado possível de transportar? Haveria dependência dos ventos para realizar a atividade da pesca? Qual a distância máxima percorrida e as direções para realizar a pesca nos diferentes tipos de embarcações?

Durante o processo de confecção das Matrizes SWOT, foram utilizados procedimentos quali-quantitativos. Primeiramente, estabeleceram-se os fatores pertencentes a cada uma das partes das matrizes, isto é, forças, oportunidades, fraquezas e ameaças. Em um segundo momento, os participantes foram conduzidos a definir níveis de importância para cada um dos fatores apresentados. Os níveis de importância seguiram a concepção da escala Likert, onde " 1 " significava "pouco importante" $\mathrm{e}$ " 5 " expressava "muito importante". Com esses procedimentos foi possível estabelecer relação de prioridade entre os fatores citados pelos participantes. 


\section{RESULTADOS E DISCUSSÃO}

A elaboração das Matrizes SWOT garantiu compreensão satisfatória dos fatores internos e externos das comunidades, demonstrando certas particularidades em algumas delas, bem como as semelhanças existentes entre elas. Por meio dos fatores indicados pelos participantes, foi possível estabelecer as vulnerabilidades existentes e as aptidões em cada uma das comunidades diante dos possíveis impactos do PEM proposto. No total, foram indicadas 36 forças, 27 fraquezas, 20 oportunidades e 13 ameaças.

As principais forças podem ser resumidas nas espécies de pescados existentes na região. A Tabela I, a seguir, lista todas as espécies citadas com seus respectivos graus de importância por comunidade. O número de espécies citadas é relevante, o que torna a avaliação de impactos um mecanismo fundamental no processo de licenciamento do projeto do CGEMAB I, pois algumas delas podem reagir de forma negativa durante as diferentes fases da obra. Brink e Dalton (2018) relataram que pescadores da região de BlockIsland (RhodeIsland, EUA) perceberam mudanças nos recursos marinhos após a introdução de um PEM com apenas 5 aerogeradores, principalmente ligadas ao habitat de determinadas espécies de peixes locais. Dessa forma, nas águas costeiras de Amontada e Itarema deve-se garantir que não ocorram significativas alterações na pesca local, assegurando a manutenção dos modos de vida local, uma vez que está planejada a inserção de 50 torres eólicas. A Matriz SWOT demonstrou que os pescadores consideram a atividade pesqueira de fundamental importância para a região, além de se sentirem motivados para continuar realizando a atividade.

Tabela I - Espécies de peixes citadas durante a elaboração das Matrizes SWOT e seus respectivos graus de importância (1 a 5) por comunidade

\begin{tabular}{|c|c|c|c|c|c|}
\hline \multirow{2}{*}{$\begin{array}{c}\text { Espécie de peixe } \\
\text { (nome popular) }\end{array}$} & \multicolumn{5}{|c|}{ Grau de importância (1 a 5) } \\
\cline { 2 - 6 } & $\begin{array}{c}\text { Caetanos de } \\
\text { Cima }\end{array}$ & $\begin{array}{c}\text { Caetanos de } \\
\text { Baixo }\end{array}$ & Moitas & $\begin{array}{c}\text { Porto dos } \\
\text { Barcos }\end{array}$ & Torrões \\
\hline Ariacó & 5 & 4 & 5 & - & - \\
\hline Arraia & - & - & 4 & - & - \\
\hline Atum & - & - & - & 5 & 5 \\
\hline Bijupirá & 5 & - & 4 & - & - \\
\hline Bonito & 5 & 5 & & - & - \\
\hline Camurupim & - & 2 & 4 & - & - \\
\hline Carapeba & - & - & 4 & - & - \\
\hline Cavala & 5 & 5 & - & - & - \\
\hline Xaréu & - & - & 4 & - & - \\
\hline Curumim & - & - & 4 & - & - \\
\hline Galo do Alto & 5 & - & - & - & - \\
\hline Guaiuba & 4 & - & - & - & - \\
\hline Guarajuba & 5 & 5 & 5 & - & - \\
\hline Lagosta & - & - & - & 5 & 5 \\
\hline Pampo & - & - & 4 & - & - \\
\hline Paru & - & - & 4 & - & - \\
\hline Polvo & - & - & - & 5 & 5 \\
\hline Robalo & - & - & 4 & - & - \\
\hline Sardinha & 3 & - & - & - & - \\
\hline Serra & 5 & 5 & 5 & - & - \\
\hline Tainha & - & - & 4 & - & - \\
\hline Ubarana & - & 1 & - & - & - \\
\hline
\end{tabular}


No que concerne às fraquezas, os resultados imprimiram algumas deficiências existentes nas comunidades. É possível perceber que algumas das fraquezas citadas, para serem suprimidas, dependem de ações de setores públicos. São carências na saúde; burocracia no licenciamento das embarcações; má fiscalização no setor trabalhista e no período de defeso da lagosta. Em Porto dos Barcos e Torrões, onde há atividades pesqueiras de maior porte, os pescadores demonstram interesses em novas formas de empréstimos financeiros e na criação de programas, projetos e planos para agregar valor aos peixes por meio de, por exemplo, empresas de beneficiamento e compras de freezers para estocagem do pescado, demonstrando, assim, aptidão em diferentes setores econômicos. Observa-se que, assim como Vanclay et al. (2015) relatam, resultados como esses, uma vez executada pela própria comunidade, poderiam ser utilizados como argumentos na busca por direitos da comunidade em diferentes setores, principalmente diante do projeto proposto.

A inserção do projeto pode afetar dois pontos julgados fortes pela comunidade de Caetanos de Cima: o uso das embarcações movidas a vento e os pontos de pescas fixos. Entende-se que a instalação do CGEMAB I na área proposta irá devastar todos os pontos de pesca que historicamente são utilizados pelos pescadores, principalmente durante o período de construção. Já no período de operação, o "efeito esteira" (nome dado à alteração ocorrida nos ventos após a inserção dos aerogeradores, cuja área projetada pode ser observada na Figura 1a) pode impedir o tráfego de embarcações movidas essencialmente pelo vento, como os paquetes e canoas, tidos como pontos fortes pelos pescadores. O estudo de alternativas locacionais, principalmente em locais mais distantes da linha da costa, pode beneficiar tanto os pescadores quanto o impacto visual na paisagem natural (Bishop \& Miller, 2007). Durante a elaboração das matrizes, as fraquezas se destacaram nas discussões diante dos demais fatores em todas as comunidades, demonstrando significativa carência a respeito de medidas que beneficiem o social.

Como oportunidade, os pescadores vislumbraram a existência de cursos profissionalizantes. Dessa forma, medidas compensatórias, a serem planejadas pelo proponente do PEM, devem priorizar a condução de projetos que entendam quais são os interesses dos comunitários, bem como demais moradores. Além disso, projetos que incentivem a pesca artesanal com foco nos jovens e estratégias para auxílio financeiro que objetivassem a construção/manutenção de frigoríficos e fábricas de gelos também se configuram como alternativas para medidas compensatórias por terem sido citadas como fraquezas, bem como serem percebidas como oportunidade com significativa importância pelos pescadores.

Por fim, há de se considerar as principais ameaças apontadas, são elas: pesca predatória, praticadas por pescadores de outras regiões e por pescadores locais, segundo os participantes de Moitas; e inserção de armadilhas proibidas e atividades turísticas intensas. Entender a existência desses fatores externos possibilita compreender a cumulatividade de impactos com aqueles que existirão a partir da introdução do CGEMAB I. Os pescadores de três comunidades afirmaram, através das Matrizes SWOT, que a construção do PEM traria grandes prejuízos à região, demostrando forte aversão ao projeto. Segundo eles, o parque promoveria: cerceamento da área de pesca; alteração na rota pesqueira; perturbações nos ventos; prejuízos às tartarugas; perdas no atrativo turístico; violação da liberdade dos pescadores e dificuldade na pesca através de jangadas, paquetes e canos a vento. 


\section{CONSIDERAÇÕES FINAIS}

Este texto objetivou avaliar, por meio da aplicação das Matrizes SWOT, os possíveis impactos sociais advindos da introdução de um PEM em águas costeiras do Ceará, o CGEMAB I. Foi possível destacar que os efeitos decorrentes da inserção de projetos eólicos no mar brasileiro, especificamente no litoral oeste do Ceará, podem gerar resultados negativos e positivos sobre os recursos biofísicos e antropológicos existentes. Entende-se que a compreensão dos impactos negativos deve ser prioridade no processo. Foi possível perceber que a participação pública através das Matrizes SWOT potencializou os resultados, identificando áreas sensíveis ao projeto. Com o foco na consecução de informações concernentes às necessidades e capacidades sociais locais, a metodologia aplicada tornou-se excelente caminho para apontar quais são os setores que reagiriam à inserção do projeto eólico-energético proposto e/ou aqueles que podem sofrer acúmulo de prejuízos.

O trabalho demonstrou que garantir a inserção social, segundo as diretrizes da AIS, promove ganhos em todas as direções. De maneira geral, os procedimentos conduzidos possibilitaram a inserção social na produção de dados para subsidiar a tomada de decisão, especificamente nas prospecções de impactos. Tais dados tornam-se basilares para uma correta construção do marco legal do setor. Além disso, durante a execução das oficinas, os debates realizados pelos pescadores culminaram em profundas reflexões sobre seus modos de vida. Portanto, as informações produzidas podem ser utilizadas para fomentar o planejamento do CGEMAB I nos municípios de Amontada e Itarema no Ceará, ao passo que a condução das matrizes reproduziu o ponto de vista comunitário, demonstrando quais são as áreas que os mesmos julgam mais importantes. Entende-se que o efetivo engajamento público deve seguir métodos que permitam transparecer as informações julgadas relevantes pelos moradores, promovendo discussões fluidas e didáticas. Por fim, este estudo demostra que os parques eólicos offshore, na realidade brasileira, não seriam tão fáceis de implementar devido aos diferentes usos do mesmo espaço físico.

Agradecimentos - Aos pescadores e representantes das respectivas colônias de pescadores que integraram a pesquisa, pela colaboração, bem como às seguintes instituições: Capes/ Print (88887.312019/2018-00), Pronem-Funcap/CNPq (0112-00068.01.00/16) e PGPSE/ Capes (88887.123947/2016-00), pelo apoio e financiamento.

\section{REFERÊNCIAS BIBLIOGRÁFICAS}

Abeeólica. Associação Brasileira de Energia Eólica. Energia Eólica chega a 14,71 GW de capacidade instalada. $1^{\circ}$ fev. 2019. Disponível em: http://abeeolica.org.br/noticias/energiaeolica-chega-a-1471-gw-de-capacidade-instalada/. Acesso em: 8 fev. 2019.

Acselrad, H. (org.). Cartografia social e território. Rio de Janeiro: IPPUR/UFRJ, 167 p., 2008.

Almasi, M.; Milow, P.; Zakaria, R. M. Participatory mangrove forest management in the Carey Island, Malaysia. Ukrainian Journal of Ecology, v. 8, n. 3, p. 293-303, 2018.

Bishop, I.D. \& Miller, D.R. Visual assessment of offshore wind turbines: the influence of distance, contrast, movement and social variables. Renewable Energy, v. 32, n. 5, p. 814831, 2007. 
Brasil. Projeto de Lei $n^{\circ}$ 484, de 2017 (do Senado Federal). Dispõe sobre a ampliação das atribuições institucionais relacionadas à Política Energética Nacional com o objetivo de promover o desenvolvimento da geração de energia elétrica localizada no mar territorial e zona econômica exclusiva a partir de fonte eólica; e dá outras providências. Diário do Congresso Nacional, Brasília, Seção I, p. 941-950, 5 dez. 2017. Disponível em: https://legis. senado.leg.br/diarios/BuscaPaginasDiario?codDiario=21194\&seq PaginaInicial=941\&seq PaginaFinal=950. Acesso em: 12 dez. 2018.

Brink, T.S.T. \& Dalton, T. Perceptions of commercial and recreational fishers on the potential ecological impacts of the Block Island Wind Farm (US). Frontiers in Marine Science, v. 5, n. November, p. 1-13, 2018.

Brown, G. \& Kyttä, M. Key issues and research priorities for public participation GIS (PPGIS): a synthesis based on empirical research. Applied Geography, v. 46, p. 126-136, 2014. Chaves, C. R. O Discurso Manifesto Jamais-Dito Do Mapa: Mapeamento Participativo. OLAM - Ciência E Tecnologia, v. 1, n. 1, p. 79-101, 2013.

Corbett, J; et al. Overview: Mapping for Change - the emergence of a new practice. Partipatory learning and action. 2006, 8p

Costa, N. O. et al. Cartografia Social Uma Ferramenta Para a Construção do Conhecimento Territorial: reflexões teóricas acerca das possibilidades de desenvolvimento do mapeamento participativo em pesquisas qualitativas. ACTA geográfica, v. Ed. Esp., n. V CBEAGT, p. 73-86, 2016.

De La Cruz-González, F.J. et al. Self-empowerment and successful co-management in an artisanal fishing community: Santa Cruz de Miramar, Mexico. Ocean and Coastal Management, v. 154, n. January, p. 96-102, 2018.

Esteves, A.M.; Franks, D. \& Vanclay, F. Social impact assessment: the state of the art. Impact Assessment and Project Appraisal, v. 30, n. 1, p. 34-42, 2012.

Faria, G.C. \& Silva, F.M. Participação pública no processo de avaliação de impacto ambiental no estado do Espírito Santo. Desenvolvimento e Meio Ambiente, v. 43, p. 139-151, 2017.

Gwec. Global Wind Report 2016 - Annual market update. Bruxelas: Global Wind Energy Council, 2017. Disponível em: http:/ / gwec.net/publications/global-wind-report-2/global -wind-report-2016/. Acesso em: 16 jan. 2018.

Helms, M. M.; Nixon, J. Exploring SWOT analysis - where are we now? A review of academic research from the last decade. Journal of Strategy and Management, v. 3, n. 3, p. 215-251, 10 ago. 2010b. Disponível em: <https://www.emerald.com/insight/content/ doi/10.1108/17554251011064837/full/html> Acesso em: 05 Fev. 2019.

ICGPSIA. Interorganizational Committee on Guidelines and Principles for Social Impact Assssment. Guidelines and Principles for Social Impact Assessment. NOAA Techinical Memorandum NMFS-F/SPO-16, n. May, p. 1-26, 1994.

Kvam, R. Avaliação de impacto social: como integrar questões sociais a projetos de desenvolvimento. Washington, D.C.: Banco Interamericano de Desenvolvimento - BID. 2018, 152 p. Disponível em: https://publications.iadb.org/pt/avaliacao-de-impacto-social-como-integrarquestoes-sociais-projectos-de-desenvolvimento. Acesso em: 2 abr. 2019.

Melo, E. Fonte eólica de energia: aspectos de inserção, tecnologia e competitividade. Estud. Av., São Paulo, v. 27, n. 77, p. 125-142, 2013. Disponível em: http://www.scielo. 
br / scielo.php?script=sci_arttext\&pid=S0103-40142013000100010\&lng=en\&nrm=iso. Acesso em: 8 fev. 2019.

Mendes, J. S.; Gorayeb, A.; Brannstrom, C. Diagnóstico Participativo e Cartografia Social Aplicados aos Estudos de Impactos das Usinas Eólicas no Litoral do Ceará: O Caso da Praia de Xavier, Camocim. Geosaberes, v. 6, n. 3, p. 243-254, 2016.

Negev, M.; Davidovitch, N.; Garb, Y. \& Tal, A. Stakeholder participation in health impact assessment: a multicultural approach. Environmental Impact Assessment Review, v. 43, p. 112-120, 2013.

Possner, A. \& Caldeira, K. Geophysical potential for wind energy over the open oceans. Proceedings of the National Academy of Sciences, v. 114, n. 43, p. 11338-11343, 24 out. 2017. Disponível em: http://www.pnas.org/lookup/doi/10.1073/pnas.1705710114. Acesso em: 18 mar. 2019.

Telles, D.H.Q. Abordagem territorial para a geografia marinha: reflexões a partir do planejamento espacial e a gestão integrada. Desenvolv. Meio Ambiente, v. 49, p. 336-354, 2018.

Vanclay, F. International principles for social impact assessment. Impact Assessment and Project Appraisal, v. 21, n. 1, p. 5-12, 2003.

Vanclay, F. et al. Social impact assessment: guidance for assessing and managing the social impacts of projects. [s.1.]. Internacional Association for Impact Assessment, 2015.

Vanclay, F. \& Esteves, A.M. Current issues and trends in social impact assessment, p. 3-19, in Vanclay, F. \& Esteves, A.M. (eds.). New directions in social impact assessment: conceptual and methodological advances, Cheltenham: Edward Elgar, 416 p., 2011.

Virtebo, J.C. Geração de energia elétrica a partir da fonte eólica offshore. 2008. Dissertação de mestrado, Departamento de Engenharia Naval e Oceânica, Escola Politécnica da Universidade de São Paulo, 168 p., São Paulo, 2008.

Yavuz, F. \& Baycan, T. Use of SWOT and analytic hierarchy process integration as a participatory decision making tool in watershed management. Procedia Technology, v. 8, 134-143, 2013.

Zheng, C.W.; Li, C.Y.; Pan, J.; Liu, M.Y. \& Xia, L.L. An overview of global ocean wind energy resources evaluations. Renewable and Sustainable Energy Reviews, v. 53, p. 1240-1251, 2016. 